\title{
Defining the role of laparoscopic liver resection in elderly HCC patients: a propensity score matched analysis
}

\author{
Phoenix Wai Yan Wong", Ka Wing Ma", Tan To Cheung, Wong Hoi She, Wing Chiu Dai, Albert Chi Yan \\ Chan, Kenneth Siu Ho Chok, Chung Mau Lo
}

Department of Surgery, Li Ka Shing Faculty of Medicine, The University of Hong Kong, Hong Kong, China.

\#Authors contributed equally.

Correspondence to: Dr. Tan To Cheung, Department of Surgery, Li Ka Shing Faculty of Medicine, The University of Hong Kong, Room 340, Block L, Queen Mary Hospital, 102 Pokfulam Road, Hong Kong, China. E-mail: cheung68@hku.hk

\begin{abstract}
How to cite this article: Wong PWY, Ma KW, Cheung TT, She WH, Dai WC, Chan ACY, Chok KSH, Lo CM. Defining the role of laparoscopic liver resection in elderly HCC patients: a propensity score matched analysis. Hepatoma Res 2021;7:45.

https://dx.doi.org/10.20517/2394-5079.2021.28
\end{abstract}

Received: 1 Mar 2021 First Decision: 22 Apr 2021 Revised: 5 May2021 Accepted: 21 May 2021 First online: 24 May 2021

Academic Editor: Ho-Seong Han Copy Editor: Xi-Jun Chen Production Editor: Xi-Jun Chen

\begin{abstract}
Aim: To elucidate the role and efficacy of laparoscopic liver resection for elderly patients with hepatocellular carcinoma (HCC).

Methods: A retrospective comparative analysis was performed between laparoscopic and open liver resection operated from year 2008 to 2018. Consecutive HCC patients aged 65 or above at the time of operation were recruited. Patients with recurrent HCC and/or alternative pathology were excluded. Short-term and long-term outcomes between the laparoscopic and the open group were compared. Propensity score matching of patients in a ratio of 1:2 was conducted before comparison.
\end{abstract}

Results: A total of 911 patients underwent hepatectomy for primary HCC from 2008 to 2018. Among them, 320 elderly patients aged over 65 years old were eligible for analysis. Heterogeneities between laparoscopic and open groups were identified namely pre-operative albumin level, aspartate transaminase, and magnitude of hepatectomy (major vs. minor). After propensity score matching of 1:2, 46 patients in the laparoscopic group and 92 patients in the open group were included for comparison. The laparoscopic group had less blood loss ( $326 \mathrm{~mL} v \mathrm{vs} .735 \mathrm{~mL} ; P<$ 0.001 ), shorter operative time (223 min vs. $324 \mathrm{~min} ; P<0.001$ ), and shorter hospital stay ( 6.3 days vs. 10.5 days; $P$ $<0.001)$. No significant differences in postoperative morbidity and hospital mortality were noted between the groups. For oncological outcome, the laparoscopic group had a superior disease-free survival $(59.7 \%$ vs. $44.5 \%$; $P$

The Author(s) 2021. Open Access This article is licensed under a Creative Commons Attribution 4.0 International License (https://creativecommons.org/licenses/by/4.0/), which permits unrestricted use, sharing, adaptation, distribution and reproduction in any medium or format, for any purpose, even commercially, as long as you give appropriate credit to the original author(s) and the source, provide a link to the Creative Commons license, and indicate if changes were made. 
$=0.041)$, and a trend towards better overall survival compared with the open group. $(78.4 \%$ vs. $64.8 \% ; P=0.110)$.

Conclusion: Laparoscopic liver resection is a safe approach for elderly patients with HCC with benefits from faster recovery and better oncological outcomes.

Keywords: Hepatectomy, open hepatectomy, laparoscopic liver resection, open liver resection, elderly, hepatocellular carcinoma, propensity score matching analysis

\section{INTRODUCTION}

With an aging population and increasing life expectancy, a growing incidence of hepatocellular carcinoma (HCC) in elderly population is expected. Pre-existing comorbidities and a diminished physiological reserve add additional concern for surgeons and anaesthetists on the planning of operations. Although open liver resection is a feasible modality in the elderly, $5 \%-40 \%$ postoperative morbidity and up to $13 \%$ hospital mortality were reported ${ }^{[1,2]}$. Laparoscopic liver resection has gained momentum in worldwide centres. Its benefits from earlier recovery, reduced blood loss and shortened hospital stay has been recognized in previous consensus conference, and has now become the standard of practice for minor liver resection ${ }^{[3-7]}$. Previous studies have shown that minimally invasive liver resection appears to be a safe and feasible option in elderly patients with malignant liver lesions ${ }^{[8-10]}$. Nonetheless, it remains unclear if similar results can be attained in elderly HCC patients, in particular on oncological outcome ${ }^{[11]}$. The aim of the study was to review on the short-term and long-term outcomes of elderly patients undergoing laparoscopic hepatectomies for HCC compared with conventional open approach. Propensity score matched analysis was performed to reduce the heterogeneity arising from selection bias and to increase the level of evidence in a nonrandomized observational study.

\section{METHODS}

From 1st January 2008 to 1 st January 2019, a total of 911 hepatectomies were performed for HCC in the Department of Surgery, Queen Mary Hospital, the University of Hong Kong. Of those patients, 320 patients aged over 65 years old were included for analysis. Data on pre-operative characteristics, intraoperative information and postoperative outcomes were reviewed. Patients were divided in two groups based on the mode of resection, the laparoscopic and the open liver resection groups. Propensity score matching with the nearest neighbouring method was conducted in 1:2 ratio between the laparoscopic and the open group before comparison. After matching, 46 patients in the laparoscopic group and 92 patients in the open group were included in this study.

\section{Preoperative evaluation}

For assessment of risk of operation and anaesthesia, a cardiopulmonary workup in the form of electrocardiogram and spirometry was undertaken for elderly patients. For patients with a high index of suspicion for occult cardiopulmonary disease, an echocardiogram and/or lung function test was performed. Patients' functional status and comorbid conditions were taken into account before surgery was offered. Liver resection was not offered to patients with an American Society of Anesthesiologists score $\geq 3$ or with significant comorbidities such as ischaemic heart disease, congestive heart failure, recent stroke, and chronic obstructive pulmonary disease.

Resectability of HCC was assessed by imaging in the form of contrast-enhanced computed tomography or magnetic resonance imaging, and treatment plan were discussed in a multi-disciplinary meeting. Patients with main portal vein invasion and/or distant metastasis were deemed unsuitable for resection, and were referred to oncologist. Laparoscopic approach was considered for tumours as per chief surgeon's discretion. 
For cirrhotic patients, only those with Child-Pugh class A or selected ones with Child-Pugh Class B were deemed suitable candidates. Liver function was assessed by liver biochemistry, platelet count, and indocyanine green clearance rate. Patients with inadequate platelet count $\left(<40 \times 10^{9} / \mathrm{L}\right.$ for minor hepatectomies or $<80 \times 10^{\%} / \mathrm{L}$ for major hepatectomies), indocyanine green clearance rate greater than $20 \%$ at $15 \mathrm{~min}$, gross ascites, or oesophageal varices were not offered resection.

All hepatectomies were performed by a single team of dedicated liver surgeons led by at least one consultant specialist. Both open and laparoscopic operations were performed in a standardized approach. Patients with significant medical risk factor will be transferred to intensive care unit (ICU) or high dependency unit postoperatively for monitoring until condition stabilized.

\section{Operative technique}

In a laparoscopic liver resection, the patient was placed in the French position with primary surgeon standing between the legs and one assistant on either side. A $30^{\circ}$ telescope was introduced with open cutdown technique. Pneumoperitoneum was maintained at 12-14 mmHg. Further 2 to 4 working ports were inserted under direct vision. Ultrasound examination was performed intra-operatively for confirmation of location, size, and number of lesions. Cavitron Ultrasonic Surgical Aspirator ${ }^{\bullet}$ (CUSA; Valleylab, Boulder, CO, USA) was used for liver parenchymal transection. Large vessels and bile duct branches were clipped and divided, whereas large segmental branches of hepatic vein were divided by endovascular staplers. The specimen was retrieved in a bag through a Pfannenstiel incision. Abdominal drain was not routinely placed. Pressure of $\mathrm{CO}_{2}$ in the peritoneum will be decreased to $8 \mathrm{mmHg}$ and arterial systolic blood pressure will be increased to around $120 \mathrm{mmHg}$ to check for bleeding. Haemostasis was achieved with bipolar diathermy, argon beam coagulator, clips, sutures, and haemostatic patches ${ }^{[10,12]}$.

In an open hepatectomy, the patient was laid in supine position. A right subcostal incision with sternal extension was employed. Intraoperative ultrasound and liver parenchymal transection were performed in a similar manner with laparoscopic resection. Pringle manoeuvre was not performed routinely unless severe bleeding was encountered. The placement of an abdominal drain was not routine ${ }^{[13]}$.

Liver segment and liver resection was defined using Couinaud classification and Brisbane classification in 2000, respectively ${ }^{[14]}$. Postoperative morbidity and mortality were assessed at 90 days after surgery according to the Clavien-Dindo classification ${ }^{[15]}$.

\section{Statistical analysis}

The baseline characteristics of patients were expressed as medians with range for continuous variables, or as frequency with percentage for categorical variable. The Mann-Whitney $U$ test was used for comparison of continuous variables, and Pearson's chi-square test was used for comparing discrete variables. The primary outcome measured was survival, while secondary outcomes were operative time, intraoperative blood loss, blood transfusion requirement, postoperative complications, and length of hospital stay. Survival analysis was performed on disease-free survival versus disease recurrence or death. The Kaplan-Meier method was used to compute survival, and the log-rank test was used for survival comparison.

Prior to comparison, data on baseline demographics, surgical characteristics and pathological findings were compared with univariate analysis to assess the clinical difference between the laparoscopic and the open groups. Propensity score analysis model was adopted to eliminate bias from case-match selection. Variables with potential influence on the outcomes were assigned propensity scores after logistic regression analysis. With propensity score computed, the nearest neighbours in the laparoscopic and open group were matched 
in 1:2 ratio accordingly. Survival outcomes in the 2 groups were then compared. Statistical significance was denoted by $P<0.05$. The computer software SPSS/PC+ (SPSS, Chicago, IL) was used for all statistical calculations.

\section{RESULTS}

A total of 911 hepatectomies were performed for the management of HCC, and among them 320 patients aged over 65 years old were identified. Seventy-nine patients (25\%) underwent pure laparoscopic hepatectomies and 241 patients (75\%) underwent open procedure. After comparing confounding factors between the two groups, significant differences in pre-operative aspartate transaminase, albumin, and magnitude of hepatectomy were identified between the groups. Propensity score matching was performed based on the variables above. Forty-six patients in the laparoscopic group and 92 patients in the open group were included in the study after propensity score matching. Three patients in the open group had initial laparoscopic approach before converting to open hepatectomy due to dense adhesions. There were no significant differences with regard to age, gender, Child grading of liver function, hepatitis status, and premorbid comorbidities. Almost all patients included in the study had cirrhosis with no differences between the groups. Cardiovascular disease was the most common comorbid condition in both groups. A comparison of baseline characteristics between the 2 groups can be viewed in Table 1.

Operative data and surgical outcomes between the groups were shown in Table 2. The magnitude and type of resection were similar between the groups. The laparoscopic group showed a shorter operative time (laparoscopic: 196 min $v$ s. open: $274 \mathrm{~min} ; P<0.001$ ), less blood loss (laparoscopic: $0.1 \mathrm{~L} v$ s. open: $0.5 \mathrm{~L} ; P<$ 0.001 ), and shorter hospital stay (laparoscopic: 5 days $v$ s. open: 8 days; $P<0.001$ ). There were no significant differences in blood transfusion requirement and postoperative complications. Postoperative ICU was required for 13 patients in the laparoscopic group and 41 patients in the open group. There was no difference in the median length of ICU stay. No hospital mortality was observed in both groups.

Regarding postoperative complications, there were 5 events in the laparoscopic group and 22 events in the open group. One patient in the open group had biliary leakage requiring endoscopic cholangiopancreatography (ERCP) and stenting. Two patients with open resection developed significant ascites postoperatively requiring paracentesis to relieve abdominal distension. Postoperative pulmonary embolism was noted in 2 patients in the open group who were treated conservatively with intravenous heparin infusion. In contrast, all complications in the laparoscopic group were of Clavien-Dindo type I to II which did not require surgical intervention. None of the patients included in the study developed cardiac or liver failure.

A comparison between pathological characteristics between 2 groups were demonstrated in Table 3. The groups had no significant differences in tumour number, tumour-node-metastasis staging, or Edmonson grading. A smaller tumour size was observed in the laparoscopic group $(3.3 \mathrm{~cm}$ in laparoscopic group $v s$. $4 \mathrm{~cm}$ in open group; $P=0.003$ ). On final pathological examination, all patients in the laparoscopic group had Ro resection. This was also achieved in all but 1 patient in the open group.

The median follow-up period for the study population was 51.4 months. The disease-free survival curve and overall survival curve were demonstrated in Figure 1 and Figure 2, respectively. The median overall survival was 85.1 months in the laparoscopic group and 75.4 months in the open group. The 1-, 3-, and 5-year overall survival rates were $97.8 \%, 88.9 \%$, and $74.7 \%$, respectively, in the laparoscopic group, and $93.2 \%$, $76.8 \%$, and $64.1 \%$, respectively, in the open group $(P=0.22)$. The median disease-free survival were more than 95 months in the laparoscopic group and 48.1 months in the open group. The 1-, 3- and 5-year 
Table 1. Patients' baseline characteristics

\begin{tabular}{|c|c|c|c|}
\hline & Open resection $(n=92)$ & Laparoscopic resection $(n=46)$ & $\boldsymbol{P}$ \\
\hline Age, years & $71(65-83)$ & $70(65-85)$ & 0.660 \\
\hline Male: female & $62: 30$ & $31: 15$ & 1.000 \\
\hline Body mass index & $23.5(14-35)$ & $24.2(17-31)$ & 0.096 \\
\hline Hepatitis B virus carrier & $68(73.9 \%)$ & $32(69.6 \%)$ & 0.590 \\
\hline Hepatitis $C$ virus carrier & $6(8.6 \%)$ & $3(6.5 \%)$ & 1.000 \\
\hline Child A disease & $91(98.9 \%)$ & $45(97.8 \%)$ & 1.000 \\
\hline Ascites & & & 0.333 \\
\hline Absent & $92(100 \%)$ & $45(97.8 \%)$ & \\
\hline Slight & $0(0 \%)$ & $1(2.2 \%)$ & \\
\hline Hemoglobin, g/dL & $13.5(9.3-16.9)$ & $13.35(6.6-15.1)$ & 0.481 \\
\hline Total bilirubin, $\mu \mathrm{mol} / \mathrm{L}$ & $11(4-70)$ & $10(3-26)$ & 0.504 \\
\hline Aspartate transaminase, IU/L & $37(16-125)$ & $37(13-133)$ & 0.586 \\
\hline Alanine transaminase, IU/L & $30.5(7-412)$ & $33(17-216)$ & 0.659 \\
\hline Creatinine, $\mu \mathrm{mol} / \mathrm{L}$ & $80(41-140)$ & $81(48-948)$ & 0.610 \\
\hline Albumin, $\mathrm{g} / \mathrm{L}$ & $42(31-54)$ & $43(32-52)$ & 0.453 \\
\hline Alpha-fetoprotein, ng/mL & $8(1-13209)$ & $18(2-517)$ & 0.741 \\
\hline$\leq 400 \mathrm{ng} / \mathrm{mL}$ & $81(88 \%)$ & $44(95.7 \%)$ & 0.219 \\
\hline$>400 \mathrm{ng} / \mathrm{mL}$ & $11(12 \%)$ & $2(4.3 \%)$ & \\
\hline International normalized ratio (admission) & $1.05(0.8-1.3)$ & $1.1(0.9-1.2)$ & 0.592 \\
\hline Platelet count $\times 10^{9} / \mathrm{L}$ & $164(68-395)$ & $145.5(47-277)$ & 0.127 \\
\hline Indocyanine green retention rate at $15 \mathrm{~min}$ & $11.5(3.7-36.3)$ & $10.9(4.2-42.5)$ & 0.052 \\
\hline Comorbidity & $68(73.9 \%)$ & $38(82.6 \%)$ & 0.254 \\
\hline Cardiovascular & $63(68.5 \%)$ & $35(76.1 \%)$ & 0.353 \\
\hline Pulmonary & $8(8.7 \%)$ & $2(4.3 \%)$ & 0.496 \\
\hline Renal & $3(3.3 \%)$ & $1(2.2 \%)$ & 1.000 \\
\hline Diabetes mellitus & $33(35.9 \%)$ & $21(45.7 \%)$ & 0.267 \\
\hline
\end{tabular}

disease-free survival rates were $87 \%, 69.9 \%$, and $59.9 \%$ in the laparoscopic group, respectively, and $76.5 \%$, $53.6 \%$, and $43.3 \%$ in the open group, respectively $(P=0.029)$. Thirty-four patients $(73.9 \%)$ in the laparoscopic group and 42 patients $(45.7 \%)$ in the open group remained disease free during the follow-up period $(P=0.002)$.

\section{DISCUSSION}

This retrospective propensity-score matched analysis demonstrated that laparoscopic hepatectomy is not only safe and feasible to elderly HCC patients, but it is associated with improved disease-free survival of about 20 months when compared to the conventional open hepatectomy group.

With increasing life expectancy, it is expected that increasing number of liver resection will be performed for elderly patients with HCC. The open approach has been shown to be a feasible option with acceptable morbidity rates and satisfactory oncological outcome in elderly patients with $\mathrm{HCC}^{[8,9,16]}$. In the era of minimally invasive surgery, laparoscopic hepatectomies in elderly patients with malignant liver tumours has demonstrated similar short-term benefits as seen in younger patients $s^{[4,1,1,12,17]}$. The role of laparoscopic approach in the management of HCC in elderly patients remains uncertain. Limited data in terms of oncological outcome and long-term survival has been reported in this population ${ }^{[18-21]}$. 
Table 2. Surgical characteristics and surgical outcomes

\begin{tabular}{|c|c|c|c|}
\hline & Open resection $(n=92)$ & Laparoscopic resection $(n=46)$ & $\mathbf{P}$ \\
\hline Blood loss, L & $0.5(0.05-9)$ & $0.1(0.01-4)$ & $<0.001$ \\
\hline With blood transfusion & $8(8.7 \%)$ & $5(10.9 \%)$ & 0.760 \\
\hline Blood replacement, $\mathrm{L}$ & $0(0-5.76)$ & $0(0-4.8)$ & 0.692 \\
\hline Total operation time, min & $274(90-914)$ & $196(65-644)$ & $<0.001$ \\
\hline Magnitude of resection & & & 1.000 \\
\hline Major & $24(26.1 \%)$ & $12(26.1 \%)$ & \\
\hline Minor & $68(73.9 \%)$ & $34(73.9 \%)$ & \\
\hline Type of resection & & & 0.109 \\
\hline Right sided hepatectomy & $14(15.2 \%)$ & $7(15.2 \%)$ & \\
\hline Left sided hepactectomy & $14(15.2 \%)$ & $16(34.8 \%)$ & \\
\hline Central bisectionectomy & $4(4.3 \%)$ & $1(2.2 \%)$ & \\
\hline Anatomical segmentectomy & $28(30.4 \%)$ & $9(19.6 \%)$ & \\
\hline Wedge resection & $32(34.8 \%)$ & $13(28.3 \%)$ & \\
\hline Patients with complication & $17(18.5 \%)$ & $5(10.9 \%)$ & 0.250 \\
\hline Number of complications & 24 & 5 & 0.205 \\
\hline General & 18 & 3 & \\
\hline Surgical & 6 & 2 & \\
\hline \multicolumn{4}{|l|}{ General complications } \\
\hline Pulmonary complications & $12(12 \%)$ & $1(2.2 \%)$ & \\
\hline Cardiac arrhythmia & $5(5.4 \%)$ & $1(2.2 \%)$ & \\
\hline lleus & 0 & $1(2.2 \%)$ & \\
\hline Urinary tract infection & $1(1.1 \%)$ & 0 & \\
\hline \multicolumn{4}{|l|}{ Surgical complications } \\
\hline Wound infection & $2(2.2 \%)$ & $2(4.3 \%)$ & \\
\hline Wound dehiscence & $1(1.1 \%)$ & 0 & \\
\hline Biliary leakage/fistula (grade B or above) & $1(1.1 \%)$ & 0 & \\
\hline Severe ascites requiring paracentesis & $2(2.2 \%)$ & 0 & \\
\hline With ICU admission & $41(44.6 \%)$ & $13(28.3 \%)$ & 0.064 \\
\hline ICU admission, day & $0(0-18)$ & $0(0-5)$ & 0.176 \\
\hline Hospital mortality & 0 & 0 & \\
\hline Hospital stay, day & $8(4-48)$ & $5(2-21)$ & $<0.001$ \\
\hline
\end{tabular}

Historically, advanced age and presence of comorbid diseases have excluded patients from liver surgery. Elderly patients represent a distinct population entity apart from younger patients. A diminished functional reserve and the presence of comorbidities put elderly patients at risk of postoperative adverse cardiac events, respiratory complications, and malnutrition. The risk of adverse cardiac events was further amplified by longer operative time and perioperative blood transfusion ${ }^{[22-25]}$. Vigilant patient selection and preoperative workup has allowed elderly patients with comorbidities to undergo laparoscopic surgery, such as colectomy and gastrectomy, with acceptable rates of complications and good long-term outcome $e^{[26-28]}$.

To our knowledge, this study is the largest series on elderly patients with HCC in comparing laparoscopic and open liver resection. All but 2 patients in this study had various degree of cirrhosis, in which increased bleeding was anticipated. Yet the laparoscopic group has demonstrated better short-term outcomes in terms of less blood loss volume, shorter operative time, and shorter hospital stay. Our study found no significant differences in overall complications between the groups. Recent studies from other centres also demonstrated satisfactory short-term outcomes with fewer complications in the laparoscopic approach $^{[10,18,19]}$. Apart from the creation of the pneumoperitoneum, advancement in haemostatic 
Table 3. Pathological characteristics

\begin{tabular}{|c|c|c|c|}
\hline & Open resection $(n=92)$ & Laparoscopic resection $(n=46)$ & $P$ \\
\hline Size of tumour, $\mathrm{cm}$ & $4(1-14)$ & $3.3(1.2-7)$ & 0.003 \\
\hline Number of tumour nodule & & & 0.106 \\
\hline 1 & $78(84.8 \%)$ & $42(91.3 \%)$ & \\
\hline 2 & $7(7.6 \%)$ & $3(6.5 \%)$ & \\
\hline 3 & $2(2.2 \%)$ & $1(2.2 \%)$ & \\
\hline Multiple & $5(5.4 \%)$ & 0 & \\
\hline Tumour pattern (solitary: multiple) & $78: 14$ & $42: 4$ & 0.284 \\
\hline Site (unilobar:bilobar) & $83: 9$ & $43: 3$ & 0.751 \\
\hline With macrovascular invasion & $4(4.3 \%)$ & 0 & 0.301 \\
\hline With microvascular invasion & $35(38 \%)$ & $18(39.1 \%)$ & 0.902 \\
\hline Nontumorous liver & & & 0.801 \\
\hline Noncirrhotic & $32(34.8 \%)$ & $17(37 \%)$ & \\
\hline Cirrhotic & $60(65.2 \%)$ & $29(63 \%)$ & \\
\hline Resection margin & & & 1.000 \\
\hline Not involved & $91(98.9 \%)$ & $46(100 \%)$ & \\
\hline Involved & $1(1.1 \%)$ & 0 & \\
\hline UICC7 & & & 0.163 \\
\hline Stage I & $46(50 \%)$ & $25(54.3 \%)$ & \\
\hline Stage II & $32(34.8 \%)$ & $18(39.1 \%)$ & \\
\hline Stage IIIA & $4(4.3 \%)$ & $2(4.3 \%)$ & \\
\hline Stage IIIB & $4(4.3 \%)$ & 0 & \\
\hline Stage IIIC & $6(6.5 \%)$ & $1(2.2 \%)$ & \\
\hline New Edmonson grading & & & 0.72 \\
\hline Well-differentiated & $14(15.2 \%)$ & $6(13 \%)$ & \\
\hline Moderately differentiated & $58(63 \%)$ & $33(71.7 \%)$ & \\
\hline Poorly differentiated & $18(19.6 \%)$ & $6(13 \%)$ & \\
\hline Necrosis & $0(0 \%)$ & $1(2.2 \%)$ & \\
\hline Not available & $1(1.1 \%)$ & $0(0 \%)$ & \\
\hline
\end{tabular}

laparoscopic device and high-definition laparoscopy with magnified view are key factors in the laparoscopic approach that facilitates transection in a cirrhotic liver ${ }^{[10]}$.

An important concern for use of laparoscopy in elderly patients is the creation of the $\mathrm{CO}_{2}$ pneumoperitoneum, with the potential of impairing ventilation in patients with diminished reserve and/or occult chronic lung disease ${ }^{[22,29,30]}$. It is worthwhile to note that our study found a trend of fewer cardiopulmonary complications in the laparoscopic group. The benefit of avoiding a subcostal, muscle cutting incision likely outweigh its potential adverse effect of transient diaphragmatic splintage during the intra-operative period.

Both the laparoscopic and the open group had similar cancer staging and Edmondson grading on final pathological examination after propensity score matching. Although there is a statistically significant differences in the tumour size between the groups, clinically, the median tumour size of the laparoscopic and the open group differed only by $0.7 \mathrm{~cm}$ which was unlikely to cause significant impact to patient's selection and prognosis. The laparoscopic group showed better disease-free survival and a trend for better overall survival, which is similar to findings in the younger patients. Less blood loss and fewer intraoperative manipulation of tumour associated with laparoscopic resection may be attributable to a better 


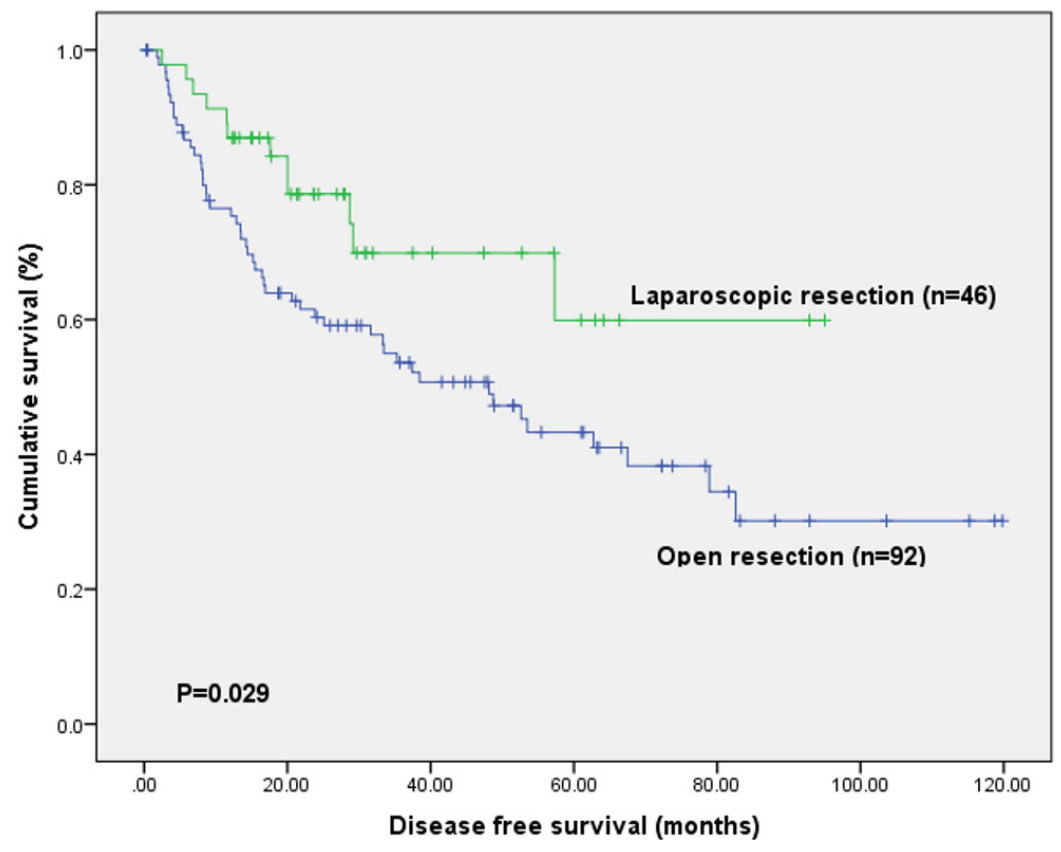

Figure 1. Disease-free survival table.

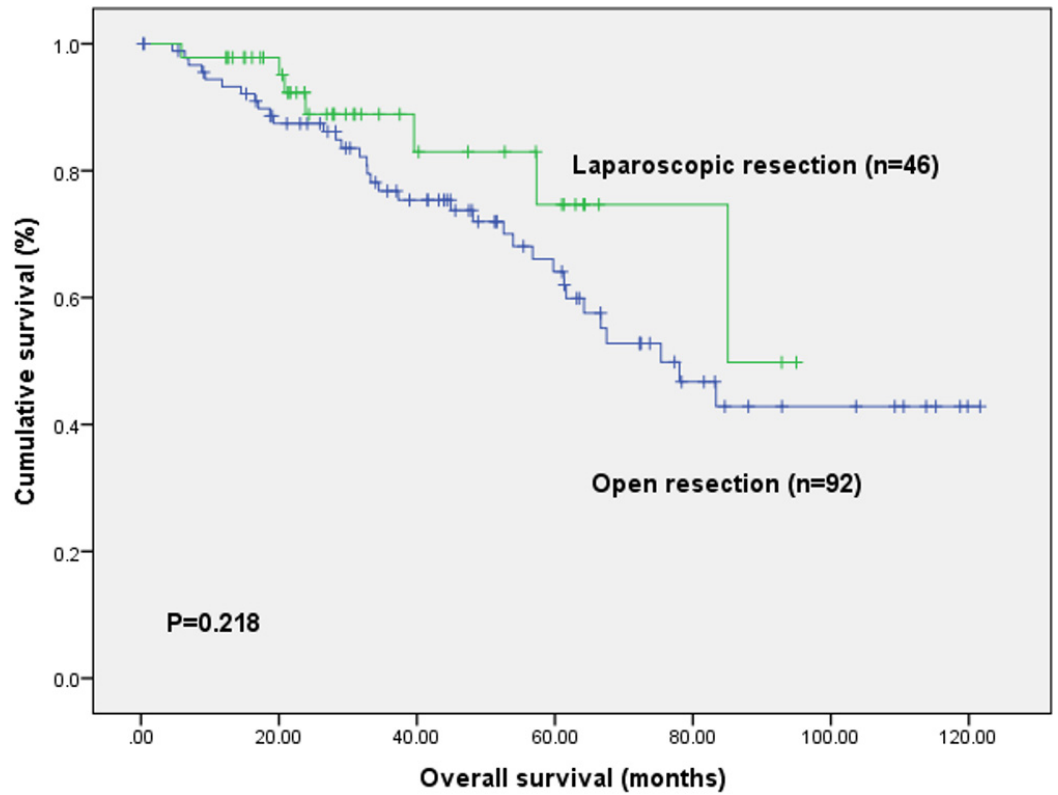

Figure 2. Overall survival table.

oncological outcome $\mathrm{e}^{[12,31]}$.

With a 10-year span of our study, the complexity of laparoscopic liver resection also progressed. Laparoscopic liver resection was classically reserved for HCC smaller than $5 \mathrm{~cm}$ due to potential technical difficulty in dissection and haemostasis ${ }^{[4]}$. In our current practise, laparoscopic resection was employed in almost all tumours that are resectable with open approach. With the improvement of technique and laparoscopic surgical armamentarium, situations like the presence of large tumour, presence of portal 
venous thrombus, need of bile duct reconstruction, and need of associating liver partition with portal vein ligation for staged hepatectomy (ALPPS) are no longer exclusive to open hepatectomy.

Improving perioperative care with multidisciplinary support from anesthetist, physiotherapist and nursing staff over the 10-year period of the study has allowed more elderly patients to be recruited for major operations. Early recovery was made possible with emphasis on early feeding, early mobilization, and pain control. Towards the end of the study (2018), our center has performed 12 laparoscopic hepatectomies on elderly patients compared with only 2 in 2008. The duration of hospitalization was similar to young counterparts for both laparoscopic and open group compared with previously published data in our center ${ }^{[0,7]}$. With continuous refinement and standardization of perioperative management, further improvement in patients' outcomes could be expected in future studies.

Due to the retrospective and non-randomized nature of the study design, it is bound to have various limitation and biases. To overcome the inherent risk of selection bias in the study population, propensity score matching was performed in an attempt to reduce the differences in covariate distribution in each group.

In conclusion, our findings suggest that laparoscopic liver resection is a safe and feasible approach for elderly HCC patients with significant benefits in short-term outcomes. It was also associated with a better oncological outcome in terms of survival. Nonetheless, further multicentred prospective studies with a larger cohort are warranted to evaluate superiority of laparoscopic hepatectomy in elderly patients.

\section{DECLARATIONS}

\section{Authors' contributions}

Conception and design of the study, critical revise of article: Ma KW, Cheung TT

Performed data analysis and interpretation, drafting the article: Wong PWY, Ma KW

Read and approved the final version of the manuscript: She WH, Dai WC, Chan ACY, Chok KSH, Lo CM

\section{Availability of data and materials}

Not applicable.

\section{Financial support and sponsorship}

None.

\section{Conflicts of interest}

All authors declared that there are no conflicts of interest.

\section{Ethical approval and consent to participate}

The study " Defining the role of laparoscopic liver resection in elderly HCC patients: a propensity score matched analysis" published in Hepatoma Research was a retrospective analysis of anonymous data. As such, it did not require specific approval from the Institutional Research Board of The University of Hong Kong since it was the policy of the Institutional Research Board that retrospective analysis of anonymous data did not require the Board's approval. All patients had given written informed consent to the use of their anonymous data for research purposes.

\section{Consent for publication}

All patients had given written informed consent to receiving their treatments and to the use including publication of their anonymous data for research purposes.

\section{Copyright}

(c)The Author(s) 2021. 


\section{REFERENCES}

1. Oishi K, Itamoto T, Kohashi T, Matsugu Y, Nakahara H, Kitamoto M. Safety of hepatectomy for elderly patients with hepatocellular carcinoma. World J Gastroenterol 2014;20:15028-36. DOI PubMed PMC

2. Poon RT, Fan ST, Lo CM, Liu CL, et al. Improving perioperative outcome expands the role of hepatectomy in management of benign and malignant hepatobiliary diseases: analysis of 1222 consecutive patients from a prospective database. Ann Surg 2004;240:698-708; discussion 708. DOI PubMed PMC

3. Buell JF, Cherqui D, Geller DA, et al; World Consensus Conference on Laparoscopic Surgery. The international position on laparoscopic liver surgery: The Louisville Statement, 2008. Ann Surg 2009;250:825-30. DOI PubMed

4. Wakabayashi G, Cherqui D, Geller DA, et al. Recommendations for laparoscopic liver resection: a report from the second international consensus conference held in Morioka. Ann Surg 2015;261:619-29. DOI PubMed

5. Xiong JJ, Altaf K, Javed MA, et al. Meta-analysis of laparoscopic vs open liver resection for hepatocellular carcinoma. World J Gastroenterol 2012;18:6657-68. DOI PubMed PMC

6. Cheung TT, Poon RT, Yuen WK, et al. Long-term survival analysis of pure laparoscopic versus open hepatectomy for hepatocellular carcinoma in patients with cirrhosis: a single-center experience. Ann Surg 2013;257:506-11. DOI PubMed

7. Cheung TT, Dai WC, Tsang SH, et al. Pure laparoscopic hepatectomy versus open hepatectomy for hepatocellular carcinoma in 110 patients with liver cirrhosis: a propensity analysis at a single center. Ann Surg 2016;264:612-20. DOI PubMed

8. Adam R, Frilling A, Elias D, et al. Liver resection of colorectal metastases in elderly patients. Br J Surg 2010;97:366-76. DOI PubMed

9. Kulik U, Framke T, Grosshennig A, et al. Liver resection of colorectal liver metastases in elderly patients. World J Surg 2011;35:206372. DOI PubMed

10. Chan AC, Poon RT, Cheung TT, et al. Laparoscopic versus open liver resection for elderly patients with malignant liver tumors: a single-center experience. J Gastroenterol Hepatol 2014;29:1279-83. DOI PubMed

11. Ferrero A, Viganò L, Polastri R, et al. Hepatectomy as treatment of choice for hepatocellular carcinoma in elderly cirrhotic patients. World J Surg 2005;29:1101-5. DOI PubMed

12. Cheung TT, Lo CM. Laparoscopic liver resection for hepatocellular carcinoma in patients with cirrhosis. Hepatobiliary Surg Nutr 2015;4:406-10. DOI PubMed PMC

13. Fan ST, Mau Lo C, Poon RT, et al. Continuous improvement of survival outcomes of resection of hepatocellular carcinoma: a 20-year experience. Ann Surg 2011;253:745-58. DOI PubMed

14. Pang YY. The Brisbane 2000 terminology of liver anatomy and resections. HPB 2000; 2:333-39. HPB (Oxford) 2002;4:99-100. DOI PubMed PMC

15. Clavien PA, Barkun J, de Oliveira ML, et al. The Clavien-Dindo classification of surgical complications: five-year experience. Ann Surg 2009;250:187-96. DOI PubMed

16. Cescon M, Grazi GL, Del Gaudio M, et al. Outcome of right hepatectomies in patients older than 70 years. Arch Surg 2003;138:54752. DOI PubMed

17. Martínez-Cecilia D, Cipriani F, Shelat V, et al. Laparoscopic versus open liver resection for colorectal metastases in elderly and octogenarian patients: a multicenter propensity score based analysis of short- and long-term outcomes. Ann Surg 2017;265:1192-200. DOI PubMed

18. Amato B, Aprea G, De Rosa D, et al. Laparoscopic hepatectomy for HCC in elderly patients: risks and feasibility. Aging Clin Exp Res 2017;29:179-83. DOI PubMed

19. Wang XT, Wang HG, Duan WD, et al. Pure laparoscopic versus open liver resection for primary liver carcinoma in elderly patients: a single-center, case-matched study. Medicine (Baltimore) 2015;94:e1854. DOI PubMed PMC

20. Notarnicola M, Felli E, Roselli S, et al. Laparoscopic liver resection in elderly patients: systematic review and meta-analysis. Surg Endosc 2019;33:2763-73. DOI PubMed

21. Spampinato MG, Arvanitakis M, Puleo F, et al. Totally laparoscopic liver resections for primary and metastatic cancer in the elderly: safety, feasibility and short-term outcomes. Surg Endosc 2013;27:1881-6. DOI PubMed

22. Turrentine FE, Wang H, Simpson VB, Jones RS. Surgical risk factors, morbidity, and mortality in elderly patients. J Am Coll Surg 2006;203:865-77. DOI PubMed

23. Tajiri K, Shimizu Y. Liver physiology and liver diseases in the elderly. World J Gastroenterol 2013;19:8459-67. DOI PubMed PMC

24. Shimada M, Takenaka K, Fujiwara Y, et al. Risk factors linked to postoperative morbidity in patients with hepatocellular carcinoma. Br J Surg 1998;85:195-8. DOI PubMed

25. Nanashima A, Abo T, Nonaka T, et al. Prognosis of patients with hepatocellular carcinoma after hepatic resection: are elderly patients suitable for surgery? J Surg Oncol 2011;104:284-91. DOI PubMed

26. Sklow B, Read T, Birnbaum E, Fry R, Fleshman J. Age and type of procedure influence the choice of patients for laparoscopic colectomy. Surg Endosc 2003;17:923-9. DOI PubMed

27. Vignali A, Di Palo S, Tamburini A, Radaelli G, Orsenigo E, Staudacher C. Laparoscopic vs. open colectomies in octogenarians: a case-matched control study. Dis Colon Rectum 2005;48:2070-5. DOI PubMed

28. Kunisaki C, Makino H, Takagawa R, et al. Efficacy of laparoscopy-assisted distal gastrectomy for gastric cancer in the elderly. Surg Endosc 2009;23:377-83. DOI PubMed

29. Korc-Grodzicki B, Downey RJ, Shahrokni A, Kingham TP, Patel SG, Audisio RA. Surgical considerations in older adults with cancer. J Clin Oncol 2014;32:2647-53. DOI PubMed 
30. Egger ME, Gottumukkala V, Wilks JA, et al. Anesthetic and operative considerations for laparoscopic liver resection. Surgery 2017;161:1191-202. DOI PubMed

31. Katz SC, Shia J, Liau KH, et al. Operative blood loss independently predicts recurrence and survival after resection of hepatocellular carcinoma. Ann Surg 2009;249:617-23. DOI PubMed 